Revista Iberoamericana, Vol. LXXI, Núm. 212, Julio-Septiembre 2005, 909-928

\title{
POR TODOS NUESTROS ANHELOS: \\ EL GÉNERO Y LA CRIANZA EN LA SERIGRAFÍA CHICANA (II TALLER MAESTRAS DE SELF HELP GRAPHICS 2001) ${ }^{1}$
}

\author{
POR \\ Yvonne Yarbro-BeJARANo \\ Stanford University
}

El II Taller Maestras de Self Help Graphics de 2001 llevaba por título “La mujer como educadora y criadora o como receptora de esa educación y crianza” [El título original del taller es: "Women as nurturers or as the nurtured"]2. Después de facilitar un telón de fondo, pasaré a analizar el tratamiento de este tema por las artistas, poniendo especial énfasis en la cuestión del género y las diversas intersecciones y contextualizaciones del tema en las diez serigrafías.

Self Help Graphics and Art, fundada en 1972 y actualmente bajo la dirección de Tomás Benítez, realiza su labor con el mismo espíritu de los centros comunitarios que surgieron durante el Movimiento Chicano. En su libro Exhibiting Mestizaje, Karen Mary Davalos contextualiza este tipo de organizaciones:

Los objetivos interrelacionados del arte y el activismo radican en el momento histórico
en el que surgieron la mayoría de museos, centros culturales y colectivos artísticos
orientados a una comunidad. Las instituciones orientadas a una comunidad, nacidas del
movimiento en pro de los derechos civiles y otros movimientos de liberación (como el
movimiento feminista y el movimiento gay/lesbiano) y sus métodos de representación
son un reflejo de la lucha social y política por la autodeterminación, la liberación y la
igualdad. Los proyectos [de tales instituciones] son protestas estratégicas contra una
historia racista y nacionalista de rechazo y negación.... que han contribuido al
restablecimiento de la memoria colectiva de los mexicanos en Estados Unidos. (62-63)

Con sede en East Los Angeles, Self Help Graphics and Art ha fomentado el desarrollo y divulgación del arte y la cultura chicanos. Algunos de sus objetivos fundacionales consistían en proporcionar una fuente de orgullo cultural y establecer un puente entre los artistas chicanos y mexicanos. ${ }^{3}$ Self Help Graphics ha prestado su apoyo a otros programas

\footnotetext{
${ }^{1}$ Mi agradecimiento a Raúl Coronado por su valiosísima ayuda en mi investigación.

${ }^{2}$ Nota de traductora: "nurturing” o "nurture" término visto en el título del taller "women as nurturers or as the nurtured" es un término complicado en español, que se ha traducido de varias maneras para acomodar los distintos contextos relacionales (familiares, amigos, mentores) que se utilizan en el texto.

${ }^{3}$ Mi agradecimiento a Barbara Carrasco (“Personal Communication”) por aportar datos e información sobre el proceso y las artistas participantes en Maestras II.
} 
y medios de expresión aparte de la impresión gráfica y la serigrafía, incluyendo la primera celebración del Día de los Muertos en Los Angeles en 1972, el muralismo, y el proyecto Barrio Mobile Art Project.

Los programas del taller de serigrafía, iniciados por la Hermana Karen Boccalero, cofundadora del programa, datan de 1983, y han dado a numerosos artistas chicanos y latinos la oportunidad de crear ediciones impresas de gran calidad artística. ${ }^{4}$ Dado que la mayoría de los participantes desde la creación del programa han sido hombres, la idea de Maestras I (Taller XXXIII) de centrarse en la obra de chicanas y otras mujeres de color fue una innovación muy bien recibida. Según Yreina Cervántez, comisaria del primer proyecto Maestras en 1999, “esta plataforma fue creada con el fin específico de impulsar la voz, la visión y la experiencia de mujeres en la tradición del arte impreso" (Taller XXXIII Maestras 2). Hoy día, los talleres de serigrafía son un acontecimiento bianual, y "Self Help Graphics está dedicada a continuar la tradición ... con otra edición del proyecto Maestras en la primavera de 2002” (Prado).

Para Maestras I, Cervántez invitó a otras diez artistas a crear serigrafías. De acuerdo con Teresa McKenna, los temas relacionados en los que se inspiraron las artistas de este primer taller de mujeres “incluían entre otros la vida y obra de Sor Juana Inés de la Cruz, otras heroínas, deidades e íconos, especialmente el erotismo y la pasión derivados de esas imágenes” (3). Las artistas participantes en este primer taller de mujeres fueron Laura Alvarez, Barbara Carrasco, Yreina Cervántez, Diane Gamboa, Pat Gómez, Margaret Guzmán, Yolanda López, Delilah Montoya, Noni Olabisi, Rose Portillo y Favianna Rodríguez. Laura E. Pérez (Estudios Etnicos, UC Berkeley) escribió un análisis de las serigrafías para el folleto de la exposición de 1999.

Esta colaboración entre artistas y especialistas continuó en Maestras II, dirigido por Barbara Carrasco, con la presencia de las artistas Laura Aguilar, Laura Alvarez, Cristina Cárdenas, Barbara Carrasco, Yvette Flores, Ester Hernández, Cristina Miguel-Mullen, Elizabeth Pérez, Shizu Saldamando y Tecpatl Vargas. Entre las especialistas se encontraban Teresa McKenna (University of Southern California), Sybil Venegas (East Los Angeles City College ) y la autora de este ensayo. La relación de McKenna con el arte chicano se manifiesta en su trabajo en el comité nacional ejecutivo de la exposición “Arte Chicano: Resistencia y Afirmación” (Chicano Art: Resistance and Affirmation o CARA) en la University of California, Los Angeles, y como editora principal del catálogo de la exposición CARA. El nombre de Venegas es bien conocido en la escena artística chicana como comisaria de exposiciones, autora de numerosos ensayos sobre el arte chicano y mentora de numerosas jóvenes artistas chicanas (Carrasco, Maestras II). Desde mi propia participación en CARA a finales de la década de los ochenta he incorporado la obra de artistas chicanas y latinas en mi enseñanza, investigaciones y publicaciones. Desde 1994 he desarrollado un archivo digital de arte chicano, en el que tiene un papel representativo la mujer.

\footnotetext{
${ }^{4}$ Para obtener información sobre Carlos Bueno, fallecido recientemente, y sobre Self Help Graphics, consultar “Carlos Bueno, 60, L.A. Art Pioneer”, página de esquelas, Los Angeles Times, miércoles, 5 de septiembre.
} 
El formato general del taller de mujeres consistía en una orientación inicial; la generación de imágenes por parte de las artistas para la edición serigráfica final previa consulta con la comisario del taller y José Alpuche, maestro impresor; una serie de mesas redondas de debate o críticas "en las que las artistas y las especialistas se reunían para debatir las dificultades técnicas del proceso de impresión así como los borradores de las imágenes y su relación con el tema elegido para el Taller” (McKenna 2); un programa que cada una de las artistas seguirían para realizar sus obras de impresión en Self Help Graphics con Alpuche y sus ayudantes Ulises Ramírez y Amos. La crítica final (19 de mayo) coincidió con un panel de debate por parte de las artistas y las críticas, celebrado en la tarde, durante el cual se exhibieron por primera vez las obras al público. Otro acontecimiento, La Exposición de Arte Impreso y Recaudación de Fondos Anual de Self Help Graphics, del 24 de junio al 29 de julio, también exhibió las serigrafías creadas en Maestras II. Las reseñas críticas de las serigrafías de mano de las especialistas se publicaron en el folleto de la exposición Taller Maestras XXXVIII. En el panel de debate el 19 de mayo, Ester Hernández presentó el argumento importante que si los proyectos de Maestras tienen como objetivo facultar plenamente a las mujeres en el terreno de la serigrafía, Self Help Graphics debería considerar seriamente nombrar un maestro impresor que sea mujer.

El tema de la crianza y la educación del segundo taller de mujeres describe el proceso del taller en sí, así como el contenido de las obras de serigrafía. Tal y como afirma Carrasco "conversamos y desarrollamos colectivamente unos diálogos visuales sobre el concepto.... durante todo el proyecto, intercambiamos opiniones sobre muchos temas y comparamos nuestras experiencias mutuas. Nuestras percepciones individuales y colectivas forman parte ahora de este Taller único" (Maestras II). Este proceso, con su énfasis en el diálogo y el apoyo, lleva a McKenna a considerar el taller como una continuación del tipo de colectivos a través de los cuales tanto las mujeres chicanas como otras mujeres de color han desarrollado su creatividad a lo largo de la historia y han ofrecido su apoyo a la de otras, pudiendo citar como ejemplo las Mujeres Muralistas de los años setenta:

En el primer Taller, el debate más amplio giró en torno a la profesionalización de las artistas y la importancia de que éstas tengan el control de sus imágenes contando con unos procedimientos adecuados de protección de sus derechos de reproducción. Las mujeres del segundo Taller dedicaron mucho tiempo a las implicaciones psicológicas y emocionales del tema de la crianza y educación. A través de este proceso, las participantes formaron una especie de comunidad que permitía a las artistas confiar sus obras a las demás, quienes ofrecían ideas constructivas y motivadoras sobre las imágenes y el proceso de materialización de las mismas en la obra impresa. Claramente, el principal atributo de cada Taller fue la colaboración.... Este conjunto de imágenes y las artistas que las crearon son el testimonio de la importancia continua que tienen los colectivos en nuestra obra artística y política. (2-3)

Al hablar de Maestras I, Yreina Cervántez destaca también la importancia de este proceso más amplio: "El conocimiento que estas mujeres pusieron en común sirvió para convertir el conjunto de toda la obra como ‘compendio’ en algo impresionante” (Maestras I 2). 
En Maestras II, las imágenes individuales y las conversaciones en grupo crearon un proceso de apoyo artístico colectivo. Comentando la dimensión intergeneracional del taller durante el panel de debate, la maestra impresora Ester Hernández se refirió a lo mucho que aprendió de las artistas más jóvenes, a la vez que Yvette Flores habló de la lección tan valiosa que había aprendido sobre cómo las mujeres pueden relacionarse sin que intervengan los celos o la competitividad. Aunque claramente unas artistas tienen más experiencia en serigrafía que otras, Carrasco califica a todas las participantes como “artistas consagradas en diversas etapas de sus carreras” (Maestras II). Esta afirmación resta importancia a las diferencias generacionales haciendo hincapié en la experiencia de cada artista. En una presentación de su obra en Stanford University, Yreina Cervántez reconoce el esquema artista "más joven/más mayor” entre las artistas chicanas, pero prefiere recalcar la "continuidad y resonancia”.

Antes de pasar a analizar cada una de las diez serigrafías y su tratamiento del tema de Maestras II, quisiera retomar algunos aspectos de las teorías feministas sobre género y crianza o educación emocional para poder comprender plenamente la aportación de las artistas a este debate continuo.

El texto clásico, The Reproduction of Mothering: Psychoanalysis and the Sociology of Gender (1978) (La reproducción de la maternidad: psicoanálisis y sociología del género) de Nancy Chodorow contribuyó a desarrollar la teoría social feminista. Su intervención llegó en un momento en que las teorías sociólogas sobre la familia naturalizaron los roles de género y presentaron unas ideas funcionalistas sobre la familia, en lugar de preguntar por qué y cómo se ha llegado a definir de manera diferente a las mujeres de los hombres en función de su género. Estas teorías aceptaban el papel “natural” de la mujer como criadora y educadora, y de los padres el rol "natural” de proveedores materiales de la familia. Chodorow dio un giro de 180 grados a este tema centrándose en cómo las mujeres se han convertido en madres (de ahí el título de su libro, la reproducción de la maternidad). Basándose en la teoría del psicoanálisis y combinándola con la teoría social, Chodorow intentó hacer algo inédito. Esta combinación fue un elemento radicalmente nuevo frente al funcionalismo que permeaba las ciencias sociales, un funcionalismo centrado en razones estructurales para el comportamiento individual. Por tanto, un funcionalista habría estudiado la forma en que las mujeres, en tanto que madres, ayudan a crear una unidad familiar que facilita la participación de las personas en la sociedad. El enfoque de Chodorow en el locus del individuo dentro de una estructura social contribuyó a la teorización de la influencia humana y las emociones dentro de las estructuras sociales.

Inspirándose en el psicoanálisis freudiano sobre relaciones-objetos, Chodorow "argumentaba que el desarrollo de las personalidades diferenciadas según el género en hombres y mujeres es tal que las mujeres tienen un impulso psicológico profundamente internalizado de reproducir el carácter íntimo de la relación con sus madres” (Laslett 306). En contraste, en un núcleo familiar donde el hombre es el principal proveedor material, "el desarrollo de la personalidad en el hombre fomenta la separación, no el vínculo, y la búsqueda de una distancia emocional, en lugar de la proximidad emocional” (306). ${ }^{5}$

\footnotetext{
${ }^{5}$ El ensayo de revisión de Barbara Laslett formaba parte de una edición especial de la publicación
} Contemporary Sociology sobre los diez libros más importantes de la disciplina. Ella ofrece una 
La respuesta feminista inmediata al libro de Chodorow fue bastante crítica, con relación a la cuestión constante de la influencia humana en contraste con la estructura social. Las aportaciones a un foro presentado originalmente en las reuniones de la American Sociological Association en 1979 y publicadas en Signs en 1981 critican a Chodorow por centrarse en las relaciones intrapsíquicas a expensas de la desigualdad social y económica. En otras palabras, para muchos, Chodorow hace hincapié en la psicología y el individuo por encima de la estructura social. Mientras que Chodorow sostiene que la crianza de los hijos debe ser más compartida entre ambos progenitores, muchas feministas argumentan que enfocarse en lograr la igualdad del hombre en la crianza de los hijos es menos importante que lograr la igualdad de ingresos para la mujer con respecto al hombre. Las ponentes criticaron a su vez la importancia que Chodorow concede al psicoanálisis y al análisis de casos concretos, puesto que su concepción teórica no se sitúa en un contexto histórico ni en un lugar particular. Consecuentemente, ella proporciona una teoría universal sobre el papel de la maternidad cuando, de hecho, se trata más bien de un concepto basado en la experiencia de madres de clase media y origen anglosajón.

En la misma edición de Signs, Chodorow contraargumenta afirmando que la maternidad forma parte de la estructura social. Detenerse en por qué las mujeres se convierten en madres no pasa por alto el aspecto social, sostiene, sino que nos obliga a comprender las restricciones sociales y los deseos individuales. A la cuestión del contexto histórico y su enfoque en mujeres de raza blanca y clase media, Chodorow desgraciadamente contesta con una respuesta muy ensayada: "Ciertamente me animaría a realizar una investigación más profunda de... las diferencias étnicas y de clase” (514).

"Chicana/o Family Structure and Gender Personality: Chodorow, Familism, and Psychoanalytic Sociology Revisited" de Denise Segura y Jennifer L. Pierce trata de utilizar las percepciones íntimas de Chodorow sin obviar su falta de especificidad cultural e histórica. Las autoras reconocen y concuerdan con la crítica a Chodorow como carente de particularidad suficiente. Tomando como núcleo su teoría de la adquisición del género, Segura y Pierce se basan en la literatura sociológica sobre las familias chicanas para desarrollar hipótesis sobre cómo las chicanas y los chicanos desarrollan sus identificaciones en función del género. Este ensayo es más sugerente que concluyente porque sus conclusiones se basan en fuentes secundarias. Las autoras sólo son capaces de vislumbrar posibilidades futuras de investigación en lugar de ofrecer un relato sobre cómo las chicanas y los chicanos diferencian sus identidades en función del género.

Segura y Pierce sugieren que las familias chicanas se diferencian significativamente de las de origen anglosajón de muy diversas formas. Las familias chicanas tienden a ser familias numerosas, multigeneracionales, de clase trabajadora y entre cuyos valores se cuentan la unidad y la solidaridad. En base a estos factores, las autoras señalan que las chicanas y los chicanos se identifican en función de su género de manera distinta a las personas de origen anglosajón porque frecuentemente existen varias figuras paternales y

revisión concisa del libro, encuadrándolo en su historia intelectual, y presenta un argumento poderoso sobre por qué debería leerse hoy y hacia dónde debería llevar la investigación actual el argumento inicial de Chodorow. 
maternales (p. ej., madrinas/padrinos, abuelos, tías y tíos). La existencia de varias figuras de este tipo en las familias chicanas define la experiencia de la crianza y educación de maneras culturalmente específicas.

Segura y Pierce están implícitamente de acuerdo con el argumento de Chodorow que afirma que "los niños comienzan a distanciarse de sus madres después de la primera infancia” (67). No obstante, ¿por qué tiene que ser necesariamente así? ¿Por qué tienen los niños que distanciarse de sus madres? ¿Se distancian siempre de sus madres? Igualmente, ¿por qué las niñas se identifican siempre con sus madres? Y si los niños se distancian de sus madres y las niñas se identifican con sus madres, ¿se debe a las expectativas de comportamiento en función del género de los padres? ¿Alientan los padres este distanciamiento e identificación? ¿Qué ocurre en el caso de niños y niñas homosexuales que se identifican con su progenitor del sexo opuesto? ¿Cómo explicamos estas identificaciones en los niños y niñas homosexuales? Ni Chodorow ni las autoras de este ensayo profundizan en esta cuestión. Al no hacerlo naturalizan su teoría de la adquisición del género.

Aunque ninguna de las obras de Maestras II lucha directamente con la heteronormatividad subyacente que sustenta a estas teorías de la crianza y la educación, las artistas ciertamente amplían el limitado enfoque familista del estudio de Chodorow y desafían sus percepciones universalistas. Como Chodorow, no consideran como algo natural la hegemonía de la mujer como criadora y educadora, sino que la representan en el contexto de las relaciones sociales; muchas destacan la influencia de la mujer y las emociones que rodean al comportamiento genérico. A diferencia de Chodorow, dotan al tema de un contexto histórico y cultural específico al tener en cuenta las desigualdades sociales y económicas, y cómo la cultura juega un papel relacionado con los modos específicos de crianza y educación emocional. Las artistas de Maestras II añaden particularidad a las teorías de crianza y educación emocional representando maneras en que las familias chicanas se diferencian de las de origen anglosajón, especialmente los aspectos multigeneracional y de clase que señalaban Segura y Pierce. El análisis (y algunas de las obras) incluye aspectos dolorosos y coercitivos de la experiencia así como los rasgos positivos asociados a la maternidad y la crianza tratados con más frecuencia. Por medio del diálogo, el tema se convirtió en un espacio conceptual donde se tratan diversos tipos y contextos de crianza y educación, que incluyen los contextos laboral y no familiar. ${ }^{6}$

Carrasco enfocó los debates sobre la crianza y educación pidiendo a las artistas que trataran el tema, “por qué somos quienes somos”. El relato de McKenna de los momentos más sobresalientes de esta exploración subraya la amplitud de las actitudes, las experiencias y las emociones que el tema suscitó y cómo éstas contribuyeron a la propia percepción personal:

\footnotetext{
${ }^{6}$ Para Venegas, “quizás los momentos más enriquecedores de nuestra reunión como artistas y especialistas para dialogar sobre las obras, la inspiración y la imaginería fueron las descripciones narrativas que describen cómo las artistas participantes recibieron esa educación, crianza o aliento. Estas narrativas se desarrollaron a partir de memorias de la infancia, de nuestro nacimiento como artistas, la amistad, la maternidad y, especialmente, de la relación de apoyo, que todos necesitamos para madurar como personas adultas y productivas”.
} 
Una artista respondió a la pregunta [de Carrasco] y al tema del Taller II replicando que a veces la crianza fracasa y ello puede ser un determinante importante de la personalidad y del propio arte. Una mujer comentó que debido al fracaso de la persona que propicia esa crianza y educación emocional, se aprende a perdonar, especialmente a perdonarse a sí mismo: "Yo alimento sus emociones [la madre] alimentando las mías propias”. Otra mujer añadió que su propia madre, “enseñaba a base de cachetadas”. Tales revelaciones llevaron al grupo a tener en cuenta el papel que juega la rabia en la determinación del propio arte y del sentido de la propia persona. Una artista afirmaba que “la rabia es una cualidad con una energía tremenda” que su madre alimentó en ella. Según explicaba otra artista "la rabia es parte del proceso de recuperación.... Se comentó que nuestra "rabia es una forma de tomar conciencia". (2-3)

Rompiendo las nociones estereotípicas de la maternidad en la cultura chicana, cada artista personaliza este tema ya sea en el contenido o en la motivación, y lo libera del tipo de confinamiento en base al género que limita la influencia de la mujer, celebrando del tema sus cualidades positivas, criticando sus aspectos negativos y reorientando su significado.

Laura Aguilar, conocida y consagrada fotógrafa en blanco y negro probó por primera vez con la serigrafía en Maestras II. Aunque su obra serigráfica Grandma se sitúa en el contexto familiar y no desafía abiertamente la normativa sexual o del género, gran parte de la fotografía de Aguilar trata directamente el lesbianismo, como sus series Latin Lesbian y Plush Pony. ${ }^{7}$ Para Davalos, la obra de Aguilar ejemplifica lo que ella denomina “crítica feminista chicana radical/lesbiana” (59). Basando sus conclusiones en su análisis de la muy promocionada obra impresa en plata-gelatina de Aguilar, Three Eagles Flying, Davalos caracteriza esta perspectiva:

La crítica feminista chicana radical/lesbiana proporciona las herramientas para recuperar historias de modalidades de representación generalmente obviadas por los nacionalismos estadounidense, mexicano y chicano... Esta posición estratégica da cuenta de las diversas experiencias de los mestizos y mestizas en su éxodo, buscando la divergencia y la complejidad en lugar de englobarla bajo el estandarte de la "comunidad" o el binario europeo-indígena, anglo-mexicano. De ahí que sea fundamental al feminismo chicano radical/lesbiano el examen del contexto de la experiencia y las modalidades de representación. (59)

En sus autorretratos desnudos, Aguilar presenta una crítica a las modalidades de representación artística históricas que dan preferencia al ideal del cuerpo femenino en el desnudo artístico, así como de la monopolización del sujeto masculino en el autorretrato.

En Grandma, Aguilar vuelve su atención sobre los numerosos contextos de la crianza y la educación emocional. La serigrafía trata el tema a través de distintas generaciones,

${ }^{7}$ Consultar Yarbro-Bejarano, "Laying It Bare: The Queer/Colored Body in Photography by Laura Aguilar”. Aguilar trata el tema de la crianza/educación fuera del contexto familiar en su serie de impresiones en plata-gelatina “Motion" (1999), que representa diversos cuerpos femeninos desnudos en plena naturaleza. Una de las impresiones se destaca respecto a este tema, al representar a la artista en una postura doblada de cintura para abajo, protegida y tocada por los cuerpos y los brazos extendidos de otras dos mujeres. 
rindiendo un mayor homenaje a su abuela y su tía abuela, ya que la madre de la artista murió cuando era pequeña. La obra impresa combina imágenes fotográficas con narrativa, adjuntando tres textos a tres imágenes. El mensaje se duplica al utilizar a la vez texto e imagen en la obra impresa con lo que se refuerza el homenaje.

La primera de las imágenes más pequeñas, en la parte superior izquierda, muestra una instantánea familiar con la abuela, el hermano de la artista (que también murió cuando ella era relativamente pequeña), la artista de niña y su tía abuela Bea. Esta fotografía está acompañada de un texto que rinde homenaje al papel que han desempeñado las dos mujeres mayores en la vida de la artista: "Mi madre me dio la vida física. Mi abuela me dio amor y me hizo sentir querida. Cuando nací prematuramente, mi madre y yo estuvimos en peligro de morir. Fue mi abuela y su hermana, la tía Bea, quienes nos sacaron adelante con su fe, tan fuertes y tan llenas de amor”.

La imagen más pequeña de la parte inferior izquierda muestra a su tía Bea consolando a la artista de pequeña. El texto demuestra la divergencia de estilos de las dos hermanas: "Con mi abuela jugaba despreocupadamente. Mi tía Bea me dio el sentimiento de seguridad y solidez con su fe y su amor por mi. Ella sigue siendo mi soporte. La tía Bea solía decir a mi abuela que viviría más tiempo si no fumara, no bebiera y no comiera carne roja. Mi abuela decía entonces a su hermana: 'Sólo se vive una vez y deberíamos disfrutar la vida sin importar nada más’”. Mientras que la tía Bea jugó un papel de crianza más tradicional en la vida de la artista, la abuela ejerció otra clase de influencia.

La imagen más grande de la abuela, a la derecha, se aparta de las representaciones tradicionales de las abuelitas en su vestimenta "masculina” (o sea, no representada de acuerdo a lo femenino), una postura informal pero firme, y en un paisaje al aire libre. El texto que la acompaña una vez más revela la complejidad del tratamiento en varios niveles que Aguilar da al tema, hablando de las distintas formas no tradicionales de crianza que su abuela le transmitió: "Sólo tuve a mi abuela durante 7 años y medio. Tengo una mejor idea de ella como mujer de la que tengo de mi madre. La tía Bea me contó tantas historias sobre mi abuela cuando era una mujer joven. Cuando pienso en mi abuela, recuerdo su sentido del humor, su amor por la jardinería y sus flores de cactus floreciendo. También le gustaba pescar e ir de acampada. Se sentía más cerca de Dios cuando se encontraba en plena naturaleza”. Como sugiere el tamaño relativo de la imagen, la abuela de Aguilar, con su espiritualidad poco ortodoxa, tiene una función mentora en el plano artístico, inspirando la fotografía reciente de Aguilar. Iniciada en la serie Nature Self-Portrait (1996) y seguida de Stillness (1999) y Motion (1999), Aguilar continúa su obra en esta línea, combinando el autorretrato desnudo y la naturaleza.

Además de proporcionar un equilibrio, el pez juguetón del margen superior derecho que encuadra la representación de la abuela y el rosario junto a la tía Bea en el margen inferior derecho reflejan el contraste entre las dos figuras criadoras y educadoras en la vida de Aguilar representadas en retratos y texto. El pez representa el amor de la abuela por la pesca y la naturaleza, donde se sentía más cerca de Dios; “el rosario indica la perspectiva opuesta de la tía, quien encontraba a Dios en la iglesia” (McKenna 2).

Distintos planteamientos sobre las fotografías utilizadas en la impresión de Aguilar producen efectos diversos en la serigrafía. Algunas fotografías (el pez, el rosario) han sido tratadas con una técnica de alto contraste que hace que parezcan gráficos. Para las tres 
imágenes principales se utilizaron medios tonos finos para conservar el aspecto fotográfico. La impresión de Aguilar ilustra el cambio que podría experimentar la imagen a través del proceso en el taller. La idea original de Aguilar necesitaba una paleta de color más brillante en chartreuse y turquesa, magenta para el rosario y el pez, que según la artista los hacía resaltar demasiado (Crítica). El amarillo pálido del fondo y los retratos color sepia del producto final crean un efecto más tranquilizador de profundidad y suavidad, evocador de sueños y recuerdos, mientras que el plateado utilizado para el pez y el rosario añade un contraste sutil pero eficaz. El color sepia da también a las fotografías un aire de antigüedad, muy apropiado sobre todo para el retrato de la abuela, realizado a principios de los años veinte. ${ }^{8}$

Barbara Carrasco se interna en la misma línea intergeneracional en Primas, donde representa el amor entre dos niñas, pero desde la perspectiva de una generación anterior. Para McKenna, “estas tiernas imágenes hablan de la crianza y educación de las familias inmediatas, especialmente entre coetáneos” (2). La crianza de las niñas por parte de la generación más mayor se presenta a través del simbolismo representado por la trenza, que rodea a las niñas de amor (los corazones alargados que salen de la trenza a la derecha y se extienden a la izquierda). En la obra de Carrasco, el cabello representa en general la femineidad tradicional, los roles de género, los valores y las costumbres. Como si quisiera denotar la ruptura de posibles ataduras, la trenza ha sido cortada. Esto indica el amor libre de cargas transmitido de una generación a otra, una crianza y educación que fomenta la fuerza y la independencia, como indica el cabello suelto al aire de la niñas. Según McKenna, "El pelo al viento de las niñas representa ... la libertad y la posibilidad de determinar su propia imagen” (2).

Carrasco, experta en impresión encontró difícil, no obstante, la producción de Primas, ya que se trataba de representar a su hija desde su propio papel de madre, un tema relativamente nuevo en su obra. El abrazo entre las primas fue espontáneo, no posado, y fue tomado con una Polaroid que la artista utilizó para su serigrafía ("Personal Communication”). Carrasco eligió el color durazno para el fondo, un bello trasfondo para los corazones color verde lima. Ese mismo verde se repite en las mangas de la niña de la izquierda. El suéter de la otra niña en turquesa unifica aún más el conjunto estética y temáticamente. De forma semejante, el cabello de las dos niñas y la trenza se han coloreado en púrpura, con reflejos azules. Carrasco crea un contraste agrandando ligeramente la imagen de la niña de la izquierda (la más mayor) y variando las tonalidades de piel, moreno claro para la prima de su hija (a la izquierda) y beige para la hija.

Al igual que Primas, Snapshot de Shizu Saldamando se centra en el vínculo generacional, aunque en este caso los sujetos son mujeres jóvenes y son amigas en lugar de familiares. La artista trabajó a partir de una fotografía de sí misma y sus dos amigas. Una de las participantes más jóvenes de Maestras II, Saldamando había realizado una serigrafía antes de este taller, además de varias monoimpresiones. Principalmente trabaja con gráficos y computadora.

\footnotetext{
${ }^{8}$ En una de las críticas McKenna notó que mientras que el sepia representa el pasado, el amarillo denota el presente, el intervalo de tiempo entre los textos. También podría decirse que el color sepia utilizado para las letras sobre el amarillo une el pasado con el presente.
} 
Saldamando fue una de las artistas que habló sobre las dificultades de su experiencia con su madre (“mi madre fomentó en mi el sentimiento de rabia”). Venegas cita ésta como la razón por la que Saldamando “encuentra apoyo entre la gente de su edad”. La imagen muestra a tres mujeres jóvenes de la misma edad, como Saldamando sugirió, aproximadamente a la que las chicas jóvenes suelen irse de casa de sus padres y compartir casa entre ellas, ayudándose las unas a las otras. La artista (la figura del medio) tiene los ojos cerrados (como en la fotografía) y está flanqueada por sus amigas. La imagen impresa da una sensación de seguridad, sugiriendo que las jóvenes pueden ser vulnerables pero se apoyan entre sí para encontrar la seguridad. Para McKenna, "Saldamando capta la cohesión de un trio de mujeres jóvenes que están unidas a pesar del hecho de estar mirando en distintas direcciones. Son un grupo de amigas que pueden ser individuales y a la vez formar parte de un colectivo" (3).

La imagen original de Saldamando permitía ver una esquina del techo. Influida e inspirada por el estilo serigráfico de Carrasco, Snapshot acabó por eliminar el fondo espacializado en favor de una ejecución gráfica plana con bordes marcados, muy diferente de "Grandma". Saldamando también recibió la influencia de los cómics y los dibujos animados japoneses. El estilo de la imagen impresa confiere un estatus de cultura popular a las tres amigas.

Snapshot coloca a sus protagonistas en una línea sobre un bello fondo de color verde claro, pero rompe la linealidad mediante variaciones en la estatura de las mujeres, colocando a la más baja en el medio y la más alta a la derecha. La artista sitúa el tema de la crianza y el apoyo intrageneracional dentro de un contexto multirracial, oscureciendo la tez de la mujer de la izquierda. A pesar de estas y otras diferencias, la obra impresa está unificada gracias a diversos elementos, especialmente el color. La mujer de la derecha lleva un suéter blanco con adorno en azul oscuro; las flores a ambos lados son de color amarillo pálido con el centro en rojo rodeadas del mismo azul que el adorno. Su collar con el nombre de la artista, “Shizu”, representa la amistad. La camiseta de la figura del centro es de color amarillo pálido con una imagen marrón en el pecho y rosa en las mangas y el hombro; el rosa reaparece en el color de labios de las tres mujeres. El adorno azul une esta figura con la de la izquierda. Las lentes de las gafas son de color turquesa pálido. La mujer de la derecha lleva un suéter de rayas marrones y blancas debajo de una chaqueta del mismo color azul que aparece en el adorno de la ropa de las otras dos figuras. La chaqueta está bordeada por un bonito reflejo salpicado en una tonalidad verde también presente en las hojas y los tallos que rodean a las flores sobre la figura de la izquierda; los pespuntes plateados de la chaqueta han sido realizados con gran elegancia. La misma tonalidad plateada ayuda a unificar la composición, utilizada en las joyas de cada una de las mujeres. El tratamiento del cabello confiere a la vez contraste y equilibrio: el cabello negro con reflejos azules de las figuras a ambos lados de la imagen; el cabello de la figura del medio tiene reflejos rosas, recogidos de la cinta del cabello de la mujer de la derecha, y se distingue más de las otras por un marcado de zigzag en blanco.

Una de las artistas más jóvenes de Maestras II, Yvette Flores es una artista de talento en su medio, el dibujo. En Greñuda, su primera serigrafía, trabajó a partir de un dibujo. La relación intergeneracional adquiere una forma diferente en la serigrafía de Flores, donde se representa un aspecto más negativo y coercitivo de la crianza. Greñuda muestra 
cómo las mujeres mayores vigilan y controlan el aspecto y el comportamiento de las niñas valiéndose de su autoridad para imponer comportamientos y un aspecto aceptables, incluyendo la longitud del cabello y el peinado. ${ }^{9}$ La artista representa esta fuerza implacable con unas manos muy grandes, caracterizadas de forma femenina mediante el barniz de uñas y la pulsera, que descienden desde la parte superior de la impresión para apaisar el cabello despeinado de la niña. Al representar solamente las manos, Greñuda no limita esta representación genérica a la madre. La imagen capta el conflicto entre la niña, que quiere ser individual, y la figura maternal, que quiere que la niña ceda a sus propósitos. Sugiere que el espíritu de la niña no será sometido tan fácilmente. La joven rebelde comunica su rabia y frustración a través de su expresión con el ceño fruncido y su postura (los brazos cruzados) y los gritos y rechazos textualizados alrededor de su figura ( ${ }_{\mathrm{i} N o !} \mathrm{i}$ No quiero! ¡Aayyii! ¡No me toques! Es mi pelo.”). “Es mi pelo” contradice la pretensión de control sobre el cuerpo y el aspecto de la niña comunica su sentimiento de ser dueña de sí misma.

Flores dibujó el texto directamente en el acetato con lápiz graso. Algunas artistas de hoy y del pasado, por ejemplo en la serigrafía de la propia Carrasco Dolores Huerta (1999), han cortado a mano las letras del texto de sus obras impresas, ya sea en un virtuoso despliegue de precisión y habilidad técnica o al uso de una computadora para generar el texto, algo prohibitivo para algunos artistas. En Maestras II, Carrasco realizó el texto de las impresiones de Aguilar y Pérez por computadora. El texto dibujado a mano de Greñuda es estética y temáticamente apropiado, pues la letra impresa parece como si hubiera sido escrita por la propia niña, y la perfección del texto generado por computadora no sería tan efectivo en esta poderosa y explosiva impresión.

El azul de la blusa de la greñuda (con reflejos en azul oscuro y amarillo) contrasta con el naranja rojizo y amarillo anaranjado de la falda. Además de la expresión facial, el lenguaje corporal y el texto, la intensidad del rechazo de la niña de esos rituales tan feminizantes también se plasma extendiendo los colores "vivos" de la falda de forma que rodean el pecho de la niña, mientras que el fondo tormentoso marrón evoca tanto la rabia como recuerda su cabello despeinado, en lo que la artista llama su “ejecución garabatosa" (Panel de debate).

The Mercury Weeps fue también la primera incursión de Tecpatl Vargas en la serigrafía, aunque ya había realizado algún trabajo de impresión en offset antes de entrar en el taller. Vargas, una de las participantes más jóvenes, se crió entre artistas chicanas y es una artista del entorno multimedia, versátil y con talento, cuya experiencia abarca el dibujo, la pintura y la escultura. Asimismo, ha trabajado con maestros impresores de Japón, fabricantes de papel y en la industria del libro.

Las imágenes de The Mercury Weeps -ampliaciones fotocopiadas confeccionadas mediante cortar y pegar de medios tonos tomadas de ediciones de las revistas Popular Science y Popular Mechanics entre los años de 1930 a 1950- parecen reproducir los roles tradicionales. La cara masculina con lentes que desciende del marco en la parte superior

\footnotetext{
${ }^{9}$ En su pintura “Torture Tradition”, Carrasco abarca el mismo tema. Su pieza muestra a una mujer joven cuyo cabello está siendo peinado tan tirante por una figura (aparentemente invisible) que los ojos se le han estirado hacia atrás al tiempo que el pelo.
} 
derecha tiene connotaciones de trabajo típicamente masculino. La cara femenina mucho más pequeña de la parte superior izquierda, los tacones y los pollos feminizados denotan la cercanía femenina a la naturaleza y el papel de la mujer como criadora: la reproducción y provisión de alimentos en forma de huevos (de gallina, de mujer) o de sí misma (carne).

A diferencia de otras obras del taller que parecen revelar su significado de una forma autosuficiente y relativamente directa, la impresión de Vargas aborda la temática de una forma mucho más cifrada. Esto trae a la luz el "privilegio cognitivo" o el acceso a información que ayuda al espectador a descifrar la imagen. Verdaderamente, este es el caso en todas las obras de impresión; por ejemplo, una lectura más allá de lo meramente estético de la obra de Hernández Con Cariño, Lydia Mendoza depende del conocimiento que se tenga de quién es Lydia Mendoza y qué tipo de relación existe entre ella y la artista. Otras se ven enriquecidas por complementos informativos específicos, como en las narrativas y otros medios que apoyan Mission in the Garden de Laura Alvarez. Durante el proceso del taller Vargas reveló que su pieza es un homenaje a su madre, quien disfrutaba leyendo revistas como Popular Mechanics. En este sentido, The Mercury Weeps apunta a una inversión de géneros intergeneracional y rinde tributo a las mujeres a través de la cultura popular.

Aun así, el conjunto de colores, con su turquesa pálido, azules, verdes y verde amarillento, crea un efecto fresco y mitigado. Las dos bombillas fluorescentes, una encendida y la otra rota o apagada, sustentan una lectura complicada. La bombilla encendida sostenida por la gallina, o figura maternal, podría verse como si iluminara el camino de la niña hacia roles no tradicionales (prácticas de lectura). La bombilla apagada o rota encima de las piernas truncadas luciendo los tacones podría sugerir la ausencia de viabilidad de los roles "femeninos" tradicionales. Este elemento junto con el cuerpo humano maternal fragmentado (cara, piernas y pies) y la figura grande de la gallina agarrando los polluelos con manos humanas intiman con unos aspectos más desconcertantes de la crianza y la educación. Esta lectura se ve apoyada por el título enigmático, por sí mismo susceptible a numerosas interpretaciones: lágrimas humanas, un objeto que "llora" como resultado de la condensación, el mercurio "llorando" de un termómetro roto (recordándonos la bombilla rota o apagada). Dadas las distintas interpretaciones sobre la crianza en esta obra impresa, la extensión vacía por el centro podría percibirse como la ausencia de algo o como la creación de un espacio para imaginar nuevos roles para las mujeres y las niñas en el presente o el futuro.

Continuando con el compromiso con una colaboración multicultural evidente en Maestras I con la participación de la artista afroamericana Noni Olabisi, Carrasco invitó a la artista pilipina Cristina Miguel-Mullen a crear una serigrafía para el segundo taller. Mangán Tayón (Let’s Eat)-Food for Thought es la primera serigrafía de Miguel-Mullen; su trabajo como artista incluye pinturas murales, multimedia interactiva, Internet, montajes y fotografía. La contribución de Miguel-Mullen a Maestras II es particularmente oportuna, dada su dedicación a representar en su obra la importancia de los pilipinos en el movimiento United Farm Workers. Ella sacó partido de su obra mural en la producción de su proyecto de impresión, realizando entrevistas y recopilando historias verbales sobre qué comidas deberían incluirse y qué recuerdos sobre comida eran los más prominentes en su familia. 
La obra Mangán Tayón es una de las cuatro serigrafías de Maestras II en las que “el texto adjunto de la madre como criadora/educadora era un centro de atención”. ${ }^{10}$ En Mangán Tayón se concede un lugar primordial a la madre preparando la comida. La impresión evoluciona desde un microcontexto a un macrocontexto, colocando la figura maternal en un marco más amplio. Según McKenna, "Miguel-Mullen intenta desvelar para nosotros la trama de los alimentos y el drama humano que hace posible nuestra alimentación” (3). La pieza reconoce el rol de la madre a la hora de mantener las tradiciones culinarias, en parte, transmitiéndolas a las generaciones más jóvenes, y celebra los alimentos como puntal de nuestra identidad cultural. Estos significados se manifiestan en la presencia de alimentos específicos, especias y productos frescos sobre la mesa, incluyendo el pescado nacional. ${ }^{11}$

En otra importante contextualización de la crianza, Mangán Tayón examina los diversos aspectos interrelacionados del consumo de alimentos, incluyendo el trabajo agrícola y el trabajo en el hogar necesario también para llevar la comida a la mesa, la diáspora pilipina, y las percepciones intolerantes y achacadas a la raza sobre la comida en la sociedad en general. En la memoria de la artista, estos aspectos sobre los alimentos están entrelazados: “Algunos de mis recuerdos favoritos son los de estar en el campo trabajando con mis primos y preparando la comida en la cocina contando historias con mi madre y hermanas" ("Information").

El origen de las imágenes de la impresión son fotos familiares tomadas en la cocina de la madre de la artista mientras cocinaba, de viejos álbumes familiares que muestran el éxodo del abuelo de la artista que formó parte de la histórica primera ola de agricultores inmigrantes de Filipinas, y su abuela que logró venir aquí como enfermera con contrato y cuidadora doméstica... las fotos históricas que se integraron en la pieza ilustran los primeros trabajadores agrícolas. ("Information”)

Mangán Tayon es un buen ejemplo de cómo el proceso de diálogo de las críticas influyó en las artistas para hacer cambios en su plan original. En lugar de crear su impresión realizando un collage de fotos, Miguel-Mullen distribuyó los elementos fotográficos en un marco de bambú.

El marco oval de bambú engloba a varias generaciones, rindiendo así homenaje simultáneamente a la madre de la artista y a sus antepasados, Se hace referencia a la riqueza alimenticia de la cocina filipina así como a la explotación laboral por el negocio agrícola de la generación del éxodo, los abuelos. El movimiento circular dentro del marco crea un flujo que vincula las generaciones además de las distintas facetas de la producción y consumo de alimentos.

Mangán Tayón es una pieza rica en texturas, de dimensionalidad compleja y una gran riqueza de color. La comida ocupa el primer plano en la parte inferior del oval, con la figura

\footnotetext{
${ }^{10}$ Venegas incluye también "las memorias autobiográficas de Yvette Flores, Greñuda”, "The Mercury Weeps de Tecpatl Vargas y Mission in the Garden de Laura Alvarez. . . un comentario visual sobre su personaje, la Sirvienta Agente Doble... inspirada por el trabajo de su madre como trabajadora del servicio doméstico.”

${ }^{11}$ La impresión incluye una piña que hace referencia al hecho de que el padre de la artista es de Hawaii.
} 
grande de la madre haciendo tallarines de arroz en el plano medio. Al fondo a la izquierda están las imágenes de los abuelos de la artista. En la parte superior derecha aparece de nuevo la abuela, y debajo de ella hay dos agricultores. Una de esas figuras está con el brazo extendido para recolectar uvas, el otro agachado. Al combinar parcialmente estas figuras con la manga de la madre, Miguel-Mullen rompe la división espacial en la impresión para dar énfasis a la continuidad temática: el trabajo en el campo, el trabajo en la casa, la producción de alimentos, la preparación de alimentos. Las conexiones temáticas también se crean a través del color. El verde del bambú se repite en el atuendo de la madre y en la ropa que llevan los trabajadores agrícolas, mientras que los tonos de color púrpura en los alimentos y los productos del primer plano se encuentran también en las uvas y en el cabello de la madre. También hay pinceladas de azul y rojo por toda la pieza, además de amarillo y dorado. El dorado del fondo, junto con el amarillo, también se aprecian en la punta de los tallarines de arroz, lo que crea un efecto como si la madre sostuviera el fuego del hogar con sus manos. Otro elemento unificador se encuentra en los hilos de vapor que salen de la comida, plasmados en plata.

Además de Snapshot, las obras serigráficas restantes tratan el concepto de la crianza fuera del contexto familiar tradicional.

Mission in the Garden es la segunda serigrafía de Laura Alvarez; su primera la produjo en Maestras I. Mission in the Garden aúna muchos de los elementos de las serigrafías analizadas anteriormente, por ejemplo, el uso de la cultura popular, un giro a las cuestiones intergeneracionales y particularmente en su colocación en el primer plano la transnacionalidad del trabajo, igual que en Mangán Tayón. Alvarez reorganiza la relación de crianza y educación intergeneracional para abordar la situación política de las niñeras que cuidan los niños de familias acomodadas a expensas de la suya propia por causa de la necesidad económica.

Mission in the Garden continúa la saga de Double Agent Sirvienta (DAS) [La Sirvienta Agente Doble]. Alvarez, artista visual y músico, desarrolla el personaje de DAS por medio de imágenes, música y narrativa. La artista construye este personaje en su sitio web:

Pon veneno en tu limpiador doméstico y entra en el mundo de la Sirvienta Agente Doble, una espía encubierta que se hace pasar por sirvienta a ambos lados de la frontera de México y Estados Unidos, y el personaje que motiva el conjunto de mi obra actual. La historia de DAS sigue a una joven en su sueño de convertirse en una estrella de telenovelas, su desencanto en la gran ciudad (D.F.), hasta su transformación en espía secreta internacional para los servicios secretos de espionaje. Al crear a DAS no sólo busco elevar la posición de las trabajadoras domésticas con un toque de humor, sino explorar además mi propia identidad entre dos culturas. La mayoría de las piezas que creo están relacionadas con la música, grabaciones realizadas en Space Station Cuba, cuya letra escribo e interpreto. ${ }^{12}$

${ }^{12}$ El CD de la opera-rock de Alvarez, The Double Agent Sirvienta está disponible en el sitio web de la artista. Es posible escuchar fragmentos de Coyote en SidroMusic.net. Algunas de sus imágenes digitales y letras se encuentran en Urban Latino Cultures. 
Alvarez pasaba de niña los veranos en un rancho en Taumaulipas, México, y continúa, como adulta, visitando el lugar. Como ella señala en su sitio web, "la combinación de estos ambientes y culturas particulares explican gran parte de la obra que realiza en la actualidad”. Parte de la inspiración para crear a DAS se deriva de las experiencias del trabajo doméstico.

En la serigrafía de Alvarez, el espacio del trabajo doméstico -diferenciado en función del género, la clase y la raza- es invadido por el mundo del espionaje y la tecnología, esta vez no polarizados sino fundidos en la figura de DAS. En un paso subversivo, la pieza sugiere que la jerarquía patrón-empleado es una vía de doble dirección que permite la actuación por parte de la trabajadora doméstica. El niño blanco puede interpretarse como parte de la élite de México, donde coinciden las jerarquías social y racial, o como un europeo-americano en los Estados Unidos. Esta indeterminación geográfica subraya la dimensión transnacional del trabajo doméstico.

En su descripción de Mission in the Garden, la artista explica la función capital del niño, así como de otros elementos de la obra impresa que forman parte de su narrativa continua de DAS:

La Sirvienta Agente Doble ... cuida e implica a un bebé rubio en sus misiones secretas mientras pasa las vacaciones en un paisaje de jardín tropical. El agente/jardinero en la lejanía es en realidad su novio de la infancia de una pequeña población colonial mexicana, pero tras su operación de cirugía tras un accidente, ella no lo reconoce. Su misión esbozada sobre la hierba con la promesa de amor y pequeñas explosiones. La información secreta escondida en un pequeño juguete.

El título de la serigrafía evoca los giros bruscos en las interpretaciones esperadas de la imagen (p. ej., la tranquilidad con que se acepta la noción de una mujer mexicana como niñera menoscabada por la presencia de tecnología subversiva en la cual el pupilo rubio juega un papel). Por un lado, la "misión” que evoca el romántico pasado español del Sudoeste resulta ser una "misión secreta“ y el jardín, con sus connotaciones de paraíso terrenal esconde una amenaza. En una de las críticas Alvarez comentó que la rica imaginería tropical respondía al hecho de que se encontraba en su primer trimestre de embarazo. También puede interpretarse a la luz de la teoría de Frances Aparicio y Susana Chávez-Silverman sobre la práctica de la "tropicalización” en virtud de la cual el paisaje tropical se reclasifica desde sus usos estereotípicos y comerciales y se llena de significados diferentes.

Construyendo una estética del estilo de los cómics brillantemente coloreada, Alvarez elige el verde claro y oscuro para la frondosa vegetación y el rosa y el amarillo vivo para las flores del jardín tropical, sobre un fondo de cielo azul. DAS, con una rodilla apoyada sobre la hierba, domina la composición. Los contrastes -su piel y ojos morenos y el cabello negro de DAS en contraposición a la piel clara, los ojos azules y el pelo rubio del niñoson resueltos por medio de las complicidades transmitidas a través del color y en la apariencia de familiaridad despreocupada, el amor y la confianza: el bebé, cuyo cuerpo aparece rodeado por el brazo de DAS, deja caer el suyo sobre la rodilla levantada de DAS. DAS lleva un vestido rosa con adorno azul, un patrón de color que se repite en el atuendo 
del niño, y el amarillo de su delantal recuerda el cabello y el juguete del niño. Sus playeras de color blanco con remate amarillo se reflejan también en la botella blanca del niño con la tetilla amarilla. La complicidad se extiende hasta el agente/jardinero, con su cortacésped rosa. De su cabeza y la de DAS sobresalen unos transmisores, así como también de la cabeza del animalito de juguete. El negro se utiliza para el micrófono oculto en la ropa de DAS, la misión secreta dibujada en la hierba y el equipo camuflado en el plumero amarillo de DAS.

En Con Cariño, Lydia Mendoza, Ester Hernández rinde homenaje a la cantante y músico pionera de la frontera tejana que se hizo famosa en la década de los años treinta en un momento en que esa trayectoria profesional era difícil para las mujeres mexicanas. Mendoza recibió el reconocimiento de la Casa Blanca por sus logros profesionales al imponerle la distinción National Heritage Medal durante la presidencia de Clinton. Hernández reorienta la crianza y la educación intergeneracional de otras obras impresas para representar la relación de tutoría y apoyo.

Después de oír que Mendoza había recibido el galardón de medalla del patrimonio nacional y que se había mudado a Fresno durante un tiempo, Hernández decidió visitarla y las dos se hicieron amigas. ${ }^{13}$ Aunque Mendoza continuó siendo una fuente de aliento y apoyo, fue especialmente a principios de los ochenta cuando su relación de tutoría y apoyo se consolidó. Este fue un momento crucial en la carrera de la artista, pues en este momento, las presiones económicas y personales estaban haciendo a Hernández plantearse si debería continuar su vida de artista. Las palabras de aliento de Mendoza reafirmaron el deseo de la artista de continuar su obra artística. En vez de dar consejos directos, la cantante ayudó a Hernández relatando los distintos caminos seguidos por ella y sus hermanas, que también se dedicaban al mundo artístico. Sus hermanas acabaron casándose, lo que puso fin a sus carreras; Mendoza, quien desde muy joven se propuso ser artista, se casó con una persona que respetaba su profesión y que comprendía la necesidad de hacer apariciones públicas y salir de gira. Esta fue una inspiración muy importante para Hernández, porque hasta entonces no había encontrado a nadie en quién fijarse como modelo que hubiera pasado por los dilemas que tanto ella como sus amigas estaban viviendo durante la era del movimiento chicano. Asimismo, Mendoza le dijo que ella tenía la responsabilidad de alimentar su don y compartirlo. La incansable dedicación de Mendoza a su arte ha sido también una fuente de inspiración para la artista.

En su relación, el apoyo emocional ha sido una vía de dos direcciones. Incluso ya en los años ochenta, Hernández ha prestado a la cantante una ayuda muy preciada, particularmente en lo que respecta al lado empresarial de la carrera de Mendoza. La devoción de la artista por Mendoza ha adquirido una importancia particular desde la serie de accidentes cerebrales que sufrió la cantante a mediados de los noventa. Con esto se cierra el círculo de apoyo emocional mutuo. Así, como bien resalta McKenna, “puesto que Lydia Mendoza arropó a Ester Hernández, nosotros nos sentimos arropados por el arte de Hernández” (2). ${ }^{14}$

${ }^{13}$ Mi agradecimiento a Ester Hernández por la información facilitada sobre su relación con Lydia Mendoza ("Personal Communication”).

${ }^{14}$ Después del primer episodio cerebral de Mendoza, Hernández filmó una entrevista con la intérprete para saber cómo estaba superando el no poder volver a tocar su música. Hernández 
Hernández ha creado entre 25 y 30 imágenes de Mendoza a lo largo de los años. ${ }^{15}$ Estas obras forman parte del proyecto artístico continuo de la artista que consiste en un homenaje a las mujeres, como ella dice, “desde diosas a travestidos” (Panel de debate). En el caso de Mendoza este arte es para Hernández otra forma de devolver algo a su amiga y mentora compartiendo su legado con otros. Cuando ella conoció a Mendoza, pocas chicanas y chicanos la conocían fuera de Texas, e incluso hoy, las generaciones jóvenes tienen poco conocimiento de su música y lo que ella representa. En esta etapa de la vida de la cantante, Con Cariño, Lydia Mendoza adquiere una nueva urgencia: "La vida de Lydia Mendoza es tan frágil y delicada en este momento, que deseo mantener vivo su espíritu y darla a conocer a la gente” ("Personal Communication”).

De su colección de cientos de imágenes fotográficas de la cantante procedentes de una variedad de fuentes, Hernández seleccionó una de la portada de un antiguo LP para su serigrafía. La motivación simbólica de esta elección tiene que ver con el hecho de que a diferencia de otras imágenes de Mendoza cuando ésta era una niña, la fotografía del LP la muestra como una mujer madura, que se sustenta en su propio talento y habilidad. Ya que esta imagen se había perdido completamente para el público, Hernández quiso traerla de nuevo a la luz.

Hernández hizo unos dibujos de la portada del álbum y utilizó la tecnología por computadora para diseñar los colores y la composición. También se influyó de los libros de arte japonés. En Con Cariño, Lydia Mendoza, la cantante aparece con elementos que marcan su identidad artística personal (la guitarra, el atuendo) sobre el fondo de una identidad colectiva más amplia: el águila de México. Para destacar la encarnación del mexicanismo en Mendoza, Hernández utiliza los colores de la bandera mexicana para su vestimenta. La representación en el fondo del águila no es semejante a la que se ve en la bandera sino más bien recuerda la cultura y el arte precolombinos. La gradación del fondo desde púrpura a lavanda proporciona el envolvente perfecto para la figura colorida de Lydia Mendoza. La laboriosa atención que Hernández presta al detalle se muestra, entre otros elementos, en "buscar la tonalidad exacta del color de carmín favorito de Mendoza, 'Cerezas en la nieve’” (McKenna 2).

El título de la serigrafía hace referencia a la forma de firmar autógrafos de Mendoza, que según Hernández, lleva a cabo con la misma sinceridad que manifiesta interpretando su música. Al mismo tiempo, es posible interpretar el título de manera que refuerce la

comenta que aunque este era un tema doloroso, consideró que era importante dar a conocer la información, puesto que tanto ella como otras personas tendrán que enfrentarse algún día a limitaciones físicas con respecto a la producción de su arte. Esta cinta de vídeo, junto con tres de los atuendos realizados a mano de Mendoza (incluyendo los que lleva en Chulas Fronteras), aproximadamente 500 fotografías y demás material relacionado con Mendoza forman parte de los Trabajos [Papers] de Ester Hernández, adquiridos recientemente por Stanford University. Special Collections de Stanford también alberga los papers de Laura Aguilar y Barbara Carrasco.

${ }^{15}$ Un componente importante de este cuerpo temático fue el montaje realizado sobre la cantante que Hernández incluyó en su muestra en solitario en el San Jose Center for the Arts a finales de los noventa. La instalación recreaba el camerino de Mendoza - con su colección de accesorios, maquillaje, zapatos y vestidos- y reflejaba el momento de la transición y transformación de "señora privada” a “diva”. 
noción del apoyo mutuo, como si la artista quisiera dirigirse a la cantante y dedicarle su serigrafía "con cariño".

Aunque primordialmente pintora, Cristina Cárdenas ha realizado varias obras impresas. Ella destaca en la experimentación con distintos tipos de papel, incluyendo la corteza de árbol, en sus creaciones serigráficas y diversos medios impresos. La artista, oriunda de México, vive actualmente en Tucson, Arizona. Cárdenas partió de un dibujo para crear su Santa Maguey, que invoca numerosos aspectos de la identidad mestiza mexicana/chicana.

El maguey es un símbolo poderoso de la identidad mexicana, que denota la fuerza, la resistencia y perdurabilidad. Asociado especialmente a la cultura indígena, el maguey alienta [nurtures] proporcionando fibra y bebida. Aparece en muchas obras de arte chicanas, por ejemplo es un motivo destacado en la obra de Santa Barraza. Tanto Juana Alicia como Terry Ybáñez representan a la deidad del maguey Mayahuel, cuya presencia es destacada en la intoxicación, las visiones y el delirio. ${ }^{16}$

A diferencia de las obras de estas artistas, donde el maguey ocupa un espacio visual prominente, en la serigrafía de Cárdenas, el maguey propiamente dicho queda oscurecido por una mujer desnuda representada con hermosura, que sólo deja a la vista tres pencas, u hojas de cactus. La cabeza con el cabello largo está inclinada hacia atrás, ligeramente ladeada a la izquierda y los brazos cruzados sobre sus pechos. Una mano agarra una penca con espinas. El doble significado del título sugiere las diversas culturas e identidades representadas en la serigrafía. Si se interpreta como Holy Maguey, la figura podría caracterizarse como otra representación de la propia Mayahuel, reconociendo la importancia cultural y espiritual de la planta. O bien, podría pensarse que la mujer adopta los atributos del cactus sagrado, resistiendo y prevaleciendo. McKenna interpreta la imagen como un gesto de amor propio, e incluso de erotismo:

La otra mano recubre su propio torso. Esta imagen subraya la importancia de la belleza y el dolor de la propia vida. La figura no sólo se sostiene a sí misma, sino que aguanta su dolor. Por este motivo ella tiene el control y se proporciona placer. (3)

Otra posible lectura del título es Saint Maguey. El "santo” de este título evoca el catolicismo, con su panteón de figuras modelo femeninas. Los brazos cruzados y el delicado giro del torso, junto con el acto de asir los bordes espinosos de la planta, evocan el martirio o las heridas y el sufrimiento causados por la censura de la Iglesia al cuerpo y la sexualidad femeninos, ilustrados aquí en las sensuales curvas de la figura femenina. Ambas lecturas son inherentes en el título, y juntas escenifican el sincretismo de varios niveles de la cultura mexicana/chicana.

\footnotetext{
${ }^{16}$ La pieza Mayahuel de Juana Alicia plasma a la hija de la artista, que lleva el nombre de la diosa, colocada en el centro de una planta maguey. En la pintura de Ybañez de 1997, una cinta como en la tradición cultural popular mexicana proclama el contenido: "Las musas de Mayahuel soñando del maguey”. Tres mujeres desnudas de piel morena, con los ojos cerrados y el cabello suelto, emergen como espectros de las pencas (hojas) del cactus. Las raíces de cuatro plantas de peyote en primer plano se entrelazan con las del maguey.
} 
Aparte del acierto artístico y la habilidad en la ejecución, el color desempeña un papel importante a la hora de transmitir el significado de la serigrafía. El cuerpo se ha realizado en un rico tono dorado, con salpicaduras y reflejos en marrón. Sobre la cabeza de la mujer pende una tela púrpura con la parte inferior en naranja rojizo. Más alejada de ésta hay otra tela, con un extremo que envuelve la hoja de cactus como si quisiera ofrecer protección contra las espinas. A un nivel más simbólico, la forma redondeada de la segunda tela sugiere un halo que rodea la cabeza de la mujer; sobre un fondo dorado se abren una estrías rojas como en abanico que parecen rayos. La prenda arrojada alrededor de las caderas de la mujer tiene un fondo blanco con dibujos turquesa, púrpura, oro, rojo y rosa. Las hojas están vivamente coloreadas en verde, púrpura, azul turquesa y amarillo pálido. El tratamiento del color, especialmente en el fondo, logra un efecto rico en texturas.

Otra serigrafía de una pintora, Ars Longa, Vita Brevis se centra en el arte propiamente dicho como fuente de apoyo. En el panel de debate, Elizabeth Pérez confesó que al principio no le sedujo el tema del taller, hasta que se dio cuenta de que la fuerza más estimulante de su vida en este momento es el arte. Tal como indica el título, su serigrafía afirma el confort y la atemporalidad del arte, que perdura después de sus creadores.

Igual que Cárdenas, Pérez se inspira en una variedad de tradiciones, señalando las diversas identidades de las mujeres chicanas. De los legados clásicos y renacentistas, toma la expresión latina y la figura desnuda de la mujer, reconocible inmediatamente en la Venus de Botticelli. La artista aísla estos elementos para hacerlos propios, plasmando a Venus como un desnudo femenino en azul sobre un fondo rojo, la antítesis de la paleta de colores pastel del pintor italiano. El rojo vivo aparece de nuevo en los labios y en el corazón. Pérez llama al color de la mujer desnuda “azul Shiva” y comenta cómo le influyó en el uso de este color el arte oriental para representar seres elevados. Basándose en esta tradición, la artista es capaz de abordar las cualidades inteligentes que las mujeres aportan al arte.

Pérez combina asimismo estos elementos con las tradiciones culturales mexicanas: el Sagrado Corazón (en el que la palabra “brevis” del adagio es visible, escrito sobre una cinta), y una versión más estilizada del aura de rayos de sol de la Virgen de Guadalupe, expresada en amarillo eléctrico. Este desdoblamiento de la iconografía religiosa relacionada con la Virgen eleva el arte desnudo femenino y el arte en sí a un nivel de veneración. Recalcando el sentido del valor propio (un tema recurrente en el taller), Pérez dota a su figura de influencia. Ella no es solamente el objeto de la mirada masculina; al darle pinceladas, Pérez la convierte en artista, una de cuyas implicaciones es que ha pintado su autorretrato.

Pérez partió de un dibujo para crear la obra impresa. Pérez, que es pintora, estudió arte en París durante varios años antes de entrar en la escena artística chicana. Como muchas otras artistas que además se desenvuelven en otros medios, el proceso serigráfico planteaba muchas dificultades y frustraciones, por ejemplo aprender a utilizar diferentes herramientas, como la cuchilla Exacto. Después de experimentar un alto grado de control en su pintura Pérez afirmó que "la producción de obras de impresión era más como un adversario" (Panel de debate). El resultado es impresionante, sobre todo teniendo en cuenta que Ars Longa, Vita Brevis era su primera serigrafía. 
De algún modo las diez serigrafías muestran quiénes son las artistas hoy día a través del examen de una relación de crianza/educación/apoyo emocional en una variedad de contextos. Sus obras aportan especificidad al debate sobre por qué las mujeres asumen roles característicos a su género o no los asumen, y cómo la crianza y educación se reproducen en condiciones culturales y económicas concretas. Ellas amplían las denotaciones y connotaciones del concepto de crianza y educación o apoyo aun conservando su valencia tradicional. Este movimiento dialéctico “dentro y contra” es característico de buena parte del arte chicano. 